\title{
Suplementação de Cloreto de Potássio para Frangos de Corte Submetidos a Estresse Calórico ${ }^{1}$
}

\author{
Sebastião Aparecido Borges ${ }^{2}$, Joji Ariki ${ }^{3}$, Cyntia Ludovico Martins ${ }^{2}$, Vera Maria Barbosa de Moraes $^{3}$
}

\begin{abstract}
RESUMO-O experimento foi realizado com objetivo de avaliar os efeitos do estresse calórico e da suplementação de cloreto de potássio $(\mathrm{KCl})$ sobre o desempenho e algumas características fisiológicas de frangos de corte. Quarenta aves, no período de 42 a 49 dias, foram submetidas ao estresse calórico $\left(16\right.$ horas a $25 \pm 1^{\circ} \mathrm{C}$; duas horas com temperatura crescente; quatro horas a $35 \pm 1^{\circ} \mathrm{C}$; e duas horas com temperatura decrescente até a termoneutralidade e com umidade relativa de $63,5 \pm 5 \%$ ), recebendo os seguintes tratamentos: $0,50 \mathrm{e} 1,00 \% \mathrm{KCl}$ na ração; 0,25 e $0,50 \% \mathrm{KCl}$ na água de bebida. A ração à base de milho e farelo de soja, com $20 \%$ de proteína bruta e $3200 \mathrm{kcal}$ EM/ $\mathrm{kg}$, foi fornecida ad libitum. A suplementação de $\mathrm{KCl}$ na ração ou na água de beber não influiu no ganho de peso, nos consumos de ração e água, na conversão alimentar, na mortalidade, na relação água/ração, no teor de matéria seca das excretas e nas características hematológicas. O estresse calórico aumentou a temperatura retal, o hematócrito, a hemoglobina, o heterófilo e a relação heterófilo/linfócito e reduziu as hemácias, o linfócito, o sódio e o potássio sérico. A suplementação de $\mathrm{KCl}$ na água regulou o número de eritrócitos e a hemoglobina em frangos estressados pelo calor. A relação heterófilo:linfócito e a temperatura retal podem ser usadas como índices de estresse.
\end{abstract}

Palavras-chave: água, cloreto de potássio, eletrólitos, estresse calórico, hematologia

\section{Potassium Chloride Supplementation in Heat Stressed Broilers}

\begin{abstract}
The experiment was conducted to estimate the effect of heat stress and the potassium chloride ( $\mathrm{KCl})$ supplementation on performance and physiological characteristics (hematological parameters, rectal temperature) of broiler chicks. Forty birds, from 42 to 49 days, were submitted to heat stress ( 16 hours in $25 \pm 1{ }^{\circ} \mathrm{C}$, two hours at increasing temperature, four hours in $35 \pm 1{ }^{\circ} \mathrm{C}$ and two hours at decreasing temperature until $25 \pm 1{ }^{\circ} \mathrm{C}$, with $63.5 \pm 5 \%$ humidity) fed the following treatments: .50 and $1.00 \% \mathrm{KCl}$ in the diet; .25 and $.50 \% \mathrm{KCl}$ in the drinking water). Corn-soybean meal diets, with $20 \%$ of crude protein and $3200 \mathrm{kcal}$ EM/kg were fed ad libitum. The weight gain, feed intake and water intake, feed:gain ratio, mortality, water:diet ratio and excreta dry matter and the hematological characteristics evaluated were not influenced by $\mathrm{KCl}$ supplementation in the diet or in the water. The heat stress increased the rectal temperature, hematocrit, hemoglobin, heterophil and the heterophil:lymphocyte ratio and decreased erythrocytes, lymphocytes and serum sodium and potassium. The $\mathrm{KCl}$ supplementation in water regulates the level of erythrocytes and hemoglobin of broilers chicks stressed by heat. The heterophil:lymphocyte ratio and rectal temperature may be used as stress index.
\end{abstract}

Key Words: water, potassium chloride, electrolytes, heat stress, hematology

\section{Introdução}

O baixo desempenho dos frangos de corte em função de temperaturas elevadas é de grande interesse de estudo em regiões quentes, especialmente quando estes animais são criados em altas densidades e o sistema de resfriamento dos galpões é ineficiente. Experimentalmente é difícil simular condições de clima quente e/ou de estresse calórico, pois o estresse é o resultado de combinações cíclicas de temperatura e umidade relativa.

O aumento da temperatura corporal, em função da exposição a temperaturas acima da zona de conforto térmico, exerce impacto negativo sobre o desempenho do animal, influenciando a eficiência alimentar, o consumo de alimento, a taxa de crescimento e a sobrevivência (MACARI et al., 1994; TINÔCO, 1995).

O sistema cardiovascular é particularmente sensível a mudanças de temperatura e constitui-se em importante indicador das respostas fisiológicas da ave a agentes estressores. Alterações quantitativas e morfológicas nas células sangüíneas podem estar associadas ao estresse calórico, traduzidas por variações nos valores de hematócrito, leucócitos circulantes, conteúdo de eritrócitos, teor de hemoglobina no eritrócito e níveis de eosinófilos (WILSON, 1971).

\footnotetext{
${ }^{1}$ Parte da Dissertação de Mestrado do primeiro autor.

2 Pós-Graduando em Zootecnia. Departamento de Zootecnia da Faculdade de Ciências Agrárias e Veterinárias - UNESP - Jaboticabal, Rodovia Carlos Tonanni, Km 5, 14870-000, Jaboticabal-SP.

${ }^{3}$ Prof. Dr. do Departamento de Zootecnia da FCAV - UNESP - Jaboticabal.
} 
O sódio $\left(\mathrm{Na}^{+}\right)$, o potássio $\left(\mathrm{K}^{+}\right)$e o cloro $\left(\mathrm{Cl}^{-}\right)$são eletrólitos fundamentais na manutenção da pressão osmótica e no balanço ácido base dos líquidos corporais. Assim, os efeitos do balanço iônico da dieta no desempenho de frangos de corte podem estar relacionados a variações no balanço ácido base (HULAN et al., 1986).

A utilização de sais via água de bebida ou ração é alternativa de manejo freqüentemente empregada pelos produtores de frangos de corte para reduzir as perdas econômicas por estresse calórico. Dentre os compostos mais usados está o KCl(SMITH e TEETER, 1993; BEKER e TEETER, 1994; AIT-BOULAHSEN et al., 1995; e BORGES et al., 1996a, b).

O objetivo deste trabalho foi avaliar os efeitos do estresse calórico e da suplementação de $\mathrm{KCl}$ na água de bebida ou na ração sobre o desempenho e os parâmetros fisiológicos de frangos de corte.

\section{Material e Métodos}

O experimento foi conduzido em sala climatizada, utilizando-se 40 frangos de corte da linhagem "Ross" com 42 dias de idade alojados em gaiolas de arame $(0,59 \times 0,58 \times 0,48 \mathrm{~m})$, equipadas com comedouros e bebedouros lineares. A sala, equipada com ar condicionado, aquecedores com termostato e circuladores de ar, manteve a temperatura e a umidade relativa do ar controladas. A temperatura foi registrada diariamente, utilizando-se termômetro de bulbo seco INCOTERM, sendo as médias máxima e mínima, respectivamente, $35,5^{\circ} \mathrm{C}$ e $24,75^{\circ} \mathrm{C}$. A umidade relativa foi obtida em termohigrógrafo SUNBEAM, com média de $63,5 \pm 5 \%$.

As aves tiveram período de adaptação de 36 horas à temperatura ambiente termoneutra de 24 a $26^{\circ} \mathrm{C}$, com rações semelhantes para todos os tratamento, sendo, após, submetidas à temperatura de estresse calórico obedecendo a seguinte seqüência diária: 16 horas em termoneutralidade $\left(24\right.$ a $\left.26^{\circ} \mathrm{C}\right)$; duas horas de temperatura crescente até atingir $34^{\circ} \mathrm{C}$; quatro horas de estresse calórico entre 34 e $36^{\circ} \mathrm{C}$; e duas horas com temperatura decrescente até atingir a termoneutralidade $\left(24\right.$ a $\left.26^{\circ} \mathrm{C}\right)$. Durante todo período experimental, que correspondeu dos 42 aos 49 dias de idade, as aves tiveram água disponível com temperatura apenas monitorada por termômetro digital modelo AL, sendo as médias máxima e mínima, respectivamente, 32,0 e $23,8^{\circ} \mathrm{C}$.

As rações experimentais, à base de milho e farelo de soja, atendendo às exigências de proteína bruta $(20 \%) \mathrm{e}$ energia metabolizável (3200 kcal/kg), sugeridas para a linhagem, e ao NATIONAL RESEARCH COUNCIL (NRC, 1994) para os demais nutrientes foram fornecidas
Tabela 1 - Composição da ração experimental Table 1 - Composition of the experimental of diet

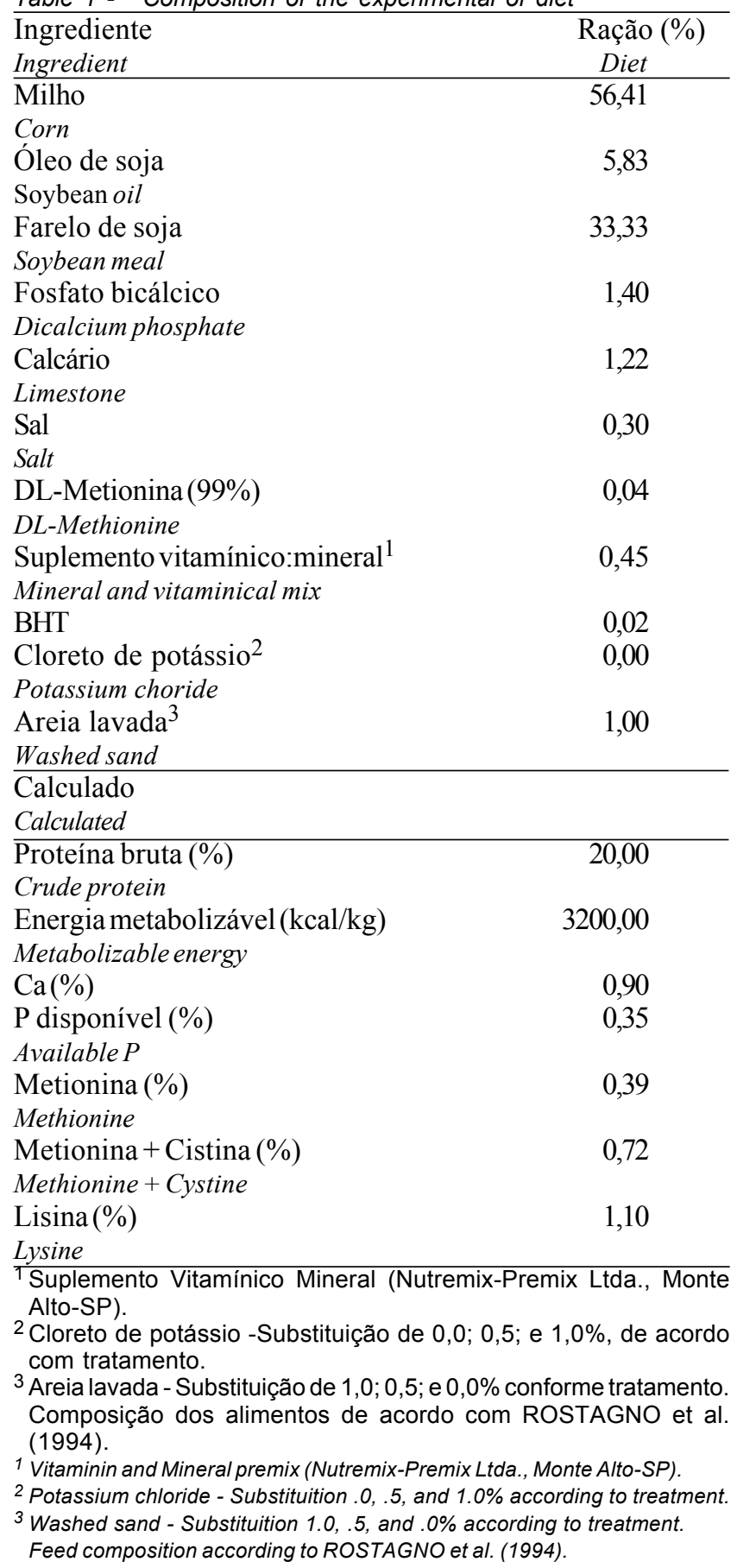

Feed composition according to ROSTAGNO et al. (1994).

à vontade (Tabela 1). $\mathrm{O} \mathrm{KCl}$ foi adicionado às rações em substituição à areia lavada.

Os tratamentos adotados foram $0,00 \%$ de suplementação de $\mathrm{KCl}$ (grupo controle), 0,50 e 1,00\% de $\mathrm{KCl}$ na ração e 0,25 e $0,50 \%$ de $\mathrm{KCl}$ na água. Foi utilizado o delineamento experimental em parcela subdividida $5 \times 2$, sendo cinco tratamentos e dois mo- 
mentos de coleta (antes e após o estresse), quatro repetições e duas aves por unidade experimental. Os resultados obtidos foram submetidos à análise estatística (BANZATTO e KRONKA, 1995) e as médias comparadas pelo teste Tukey ( $5 \%$ de probabilidade).

Ganho de peso, consumo de ração, conversão alimentar, consumo de água, relação consumo de água/consumo de ração, mortalidade e umidade das excretas foram avaliados no final do período. Para cada repetição foi feita coleta total das excretas duas vezes ao dia (antes e depois do estresse). Ao final, as amostras totais de cada parcela foram homogeneizadas, compondo única amostra por parcela. A determinação da umidade foi obtida pelo método da secagem em estufa com ventilação forçada a $55 \pm 5{ }^{\circ} \mathrm{C}$ por 72 horas e a avaliação por diferença de peso em balança digital modelo B - 6000 com precisão de um grama $(1 \mathrm{~g})$.

Amostras de sangue venoso $(3 \mathrm{~mL})$ foram coletadas com seringas esterilizadas no início (42 dias) e no final do experimento (49 dias) por punção da veia da asa em todas as aves da parcela. As amostras foram identificadas e fracionadas: $2 \mathrm{~mL}$ em tubo de ensaio, dessoradas em centrífuga EXCELSA 2 modelo $205 \mathrm{~N}$ por cinco minutos a 3000 rpm e destinadas às análises de $\mathrm{Na} \mathrm{e} \mathrm{K}$, e $1 \mathrm{~mL}$ em frasco contendo anticoagulante EDTA, destinadas às análises para número de hemácias, hematócrito, hemoglobina, heterófilo e linfócito e calculada a relação heterófilo/linfócito.

A contagem de hemácias foi obtida por diluição de $0,02 \mathrm{~mL}$ de sangue em diluidor automático CELM DA 500 e posterior contagem automática no aparelho CELM CC 510. Os resultados foram obtidos diretamente e expressos em número de células $\mathrm{X} 10^{6}$ por $\mathrm{mm}^{3}$.

$\mathrm{O}$ hematócrito foi determinado pelo método do MICRO HEMATÓCRITO, que consiste na introdução das amostras de sangue em tubos capilares (75 mm de comprimento por 1,4-1,6 mm de diâmetro com volume de 80 microlitros), com posterior centrifugação a $11.000 \mathrm{rpm}$ por cinco minutos. A leitura foi realizada por meio de tabela apropriada, sendo os valores expressos em porcentagem.

A concentração de hemoglobina foi determinada pelo método de CIANOMETAHEMOGLOBINA. As células foram hemolisadas e centrifugadas por 5 minutos a $3000 \mathrm{rpm}$ em centrífuga universal (CENTRIFUGADOR EXCELSA 2 FANEM). A leitura foi feita em espectrofotômetro (CELM E-225 D), em comprimento de onda de $540 \mathrm{~nm}$, e os valores expressos em grama por decilitro $(\mathrm{g} / \mathrm{dL})$.

A contagem diferencial (100 células/campo) de heterófilos elinfócitos foirealizada pormicroscopiaóptica, em objetiva de imersão, de esfregaço sanguíneo corado por ROSENFELD e os resultados expressos em porcentagem. A dosagem de Nae K foi feita pela METODOLOGIA DO ESPECTROFOTÔMETRO DE CHAMA - FC180 - CELM e os resultados expressos em mmol/L.

A temperatura retal foi obtida diariamente por meio da introdução de sonda (YSI, $\mathrm{n}^{0} 702$ conectada a termômetro YSI, 46 TUC), na cloaca de todas as aves experimentais, antes e após o estresse, sendo realizada a leitura após a estabilização da temperatura.

\section{Resultados e Discussão}

Os resultados de ganho de peso, consumo de ração e conversão alimentar são apresentados na Tabela 2. Não houve efeito da suplementação de $\mathrm{KCl}$, tanto na ração como na água, independentemente dos níveis adicionados, sobre o desempenho dos frangos submetidos a estresse calórico. Estes resultados diferem dos obtidos por SMITH e TEETER (1989; 1992) e BEKER e TEETER (1994), que constataram resposta favorável da suplementação de $\mathrm{KCl}$ para aves estressadas pelo calor. Do mesmo modo, BORGES et al. (1996a) verificaram aumento no ganho de peso e no consumo de ração dos frangos de corte durante o verão, em razão da suplementação de $\mathrm{KCl}$.

Embora BELAY e TEETER (1993) tenham estabelecido relação positiva entre a ingestão de $\mathrm{K}^{+}$e a capacidade de sobrevivência das aves, os resultados obtidos neste trabalho não permitem inferir sobre este parâmetro, pois apenas um animal morreu, embora todos apresentassem o comportamento característico de estresse calórico.

$\mathrm{O}$ ambiente controlado no qual foi conduzido o experimento permite inferir que a resposta das aves à suplementação com $\mathrm{KCl}$ pode estar ligada a tempo (horas), período (dias) e intensidade (temperatura) de estresse e que a concentração de $\mathrm{KCl}$ a ser adicionada pode estar relacionada com a intensidade do estresse.

Consumo de água, relação água/ração e matéria seca das excretas (\%) não foram influenciados pelo $\mathrm{KCl}$, tanto na água como na ração (Tabela 2). No entanto, BORGES et al. (1996a) constataram aumento significativo no consumo de água e na relação água/ração, com a suplementação de $\mathrm{KCl}$ na ração, o que está relacionado ao número de dias e à quantidade suplementada.

Os resultados de temperatura retal, hematócrito, heterófilo, linfócito, relação heterófilo/linfócito e potássio sérico são apresentados na Tabela 3. Neste estudo a temperatura ambiente excedeu o limite 
BORGES et al.

Tabela 2 - Ganho de peso (GP), consumo de ração (CR), conversão alimentar (CA), consumo de água $(A G)$, relação água:ração (AG:CR) e matéria seca das excretas (MS) em frangos de corte suplementados com $\mathrm{KCl}$ e submetidos a estresse calórico

Table 2 - Weight gain (WG), feed intake (FI), feed:gain ratio (F:G), water intake (WI), water:diet ratio (WI:FI) and excretion dry matter (DM) in broilers supplemented with $\mathrm{KCl}$ and submitted to heat stress

\begin{tabular}{lcccccc}
\hline $\mathrm{KCl}$ & \multicolumn{5}{c}{ Parâmetro(Parameter) } \\
\cline { 2 - 7 }$(\%)$ & $\begin{array}{c}\mathrm{GP}(W G) \\
(\mathrm{kg})\end{array}$ & $\begin{array}{c}\mathrm{CR}(F I) \\
(\mathrm{kg})\end{array}$ & $\mathrm{CA}(F: G)$ & $\begin{array}{c}\mathrm{AG}(W I) \\
(\text { litros })\end{array}$ & $\begin{array}{c}\mathrm{AG}: \mathrm{CR} \\
(\text { litros/kg) }\end{array}$ & $\begin{array}{c}\mathrm{MS}(D M) \\
(\%)\end{array}$ \\
\hline $\begin{array}{l}\text { Controle } \\
\text { Control }\end{array}$ & & & & & & \\
$\quad 0,00$ & 0,37 & 0,99 & 2,71 & 2,98 & 3,01 & 21,67 \\
$\begin{array}{c}\text { Ração } \\
\text { Diet }\end{array}$ & & & & & & \\
0,50 & 0,37 & 0,97 & 2,63 & 2,94 & 3,03 & 24,79 \\
1,00 & 0,38 & 1,02 & 2,78 & 3,43 & 3,35 & 21,84 \\
Água & & & & & & \\
Water & 0,38 & 0,92 & 2,51 & 3,07 & 3,30 & 21,92 \\
0,25 & 0,43 & 0,98 & 2,30 & 3,33 & 3,40 & 22,23 \\
0,50 & 18,51 & 6,98 & 17,16 & 17,05 & 13,03 & 13,53 \\
CV $(\%)$ & & & & &
\end{tabular}

considerado ideal por aproximadamente 8 horas por dia, provocando aumento $(\mathrm{P}<0,01)$ da temperatura retal das aves, corroborando os resultados obtidos por MAY et al. (1987). Esses autores sugeriram o uso da temperatura retal como indicador de estresse, uma vez que essa temperatura é considerada real, ou seja, próxima daquela do centro orgânico. Porém, a suplementação de $\mathrm{KCl}$ não influenciou a temperatura retal, discordando de SMITH e TEETER (1989) e AIT-BOULAHSEN et al. (1995). O menor valor de temperatura retal, encontrado por esses autores, poderia estar relacionado com o maior consumo de água, que por sua vez aumenta a eficiência na perda de calor evaporativo e, conseqüentemente, a dissipação de calor (BELAY e TEETER, 1993), possibilitando a diminuição da temperatura retal de aves expostas a estresse calórico (WIERNUSZ e TEETER, 1993). Assim, como as aves tinham água disponível durante todo período de estresse, é provável que este parâmetro tenha interferido na manutenção da temperatura corporal, favorecendo a sobrevivência das mesmas, mesmo considerando que a temperatura máxima da água durante o estresse tenha atingido $32,0^{\circ} \mathrm{C}$, enquanto na termoneutralidade a temperatura média foi de $23,8^{\circ} \mathrm{C}$.

$\mathrm{O}$ estresse calórico provocou aumento $(\mathrm{P}<0,05)$ no hematócrito (Tabela 3), confirmando os resultados de McFARLANE et al. (1989), o que poderia estar associadoà perda de água do organismo. Contudo, os resultados contrariam diversos autores (MAXWELL et al., 1990; FURLAN, 1992; CISCATO, 1995), em que o estresse térmico provocou redução no valor do hematócrito. A suplementação de $\mathrm{KCl}$ não influenciou o hematócrito. Todavia, o valor do hematócrito não pode ser analisa- do individualmente, pois pode ser influenciado pelo tamanho e número de células sangüíneas.

A porcentagem de heterófilos aumentou e a de linfócitos reduziu $(\mathrm{P}<0,01)$ em razão do estresse calórico (Tabela 3), concordando com os resultados obtidos por McFARLANE et al. (1989). Não houve interação entre o estresse calórico e a suplementação de $\mathrm{KCl}$ para essas variáveis. A relação heterófilo/ linfócito aumentou $(\mathrm{P}<0,01)$ após o estresse calórico, confirmando a proposição de McFARLANE e CURTIS (1989), MACARI et al. (1994) e ZULKIFLI e SIEGEL (1995) de que a relação heterófilo/linfócito é bom indicativo de estresse calórico. No entanto, não houve influência $(\mathrm{P}>0,05)$ do $\mathrm{KCl}$ sobre esta relação.

$\mathrm{O}$ estresse provocou redução $(\mathrm{P}<0,01)$ nos níveis séricos de $\mathrm{K}^{+}$(Tabela 3 ), confirmando os resultados de DEYHIM et al. (1990), BELAY e TEETER (1993) e AIT-BOULAHSEN et al. (1995). Entretanto, os resultados obtidos neste trabalho diferem dos encontrados por BOTURA (1993), embora esse autor não tenha utilizado qualquer espécie de aditivo suplementar. A diminuição nos níveis séricos de $\mathrm{K}^{+}$pode estar relacionada a possível aumento na excreção urinária deste íon, de acordo com as proposições de DEETZ e RINGROSE (1976) e DEYHIM et al. (1990), em que aves termoestressadas excretam mais $\mathrm{K}^{+}$que as criadas em ambiente termoneutro. Não se observou interação entre o estresse calórico e a suplementação de $\mathrm{KCl}$. Do mesmo modo, BORGES et al. (1996b) não observaram interação entre o $\mathrm{KCl}$ adicionado às rações de frangos de corte durante o verão e os níveis séricos de $\mathrm{K}^{+}$.

A contagem de hemácias não foi influenciada pelo estresse calórico (Tabela 4), quando as aves 
Rev. bras. zootec.

Tabela 3 - Temperatura retal $(T R)$, hematócrito $(\mathrm{Ht})$, heterófilo $(\mathrm{H})$, linfócito $(\mathrm{L})$, relação heterófilo:linfócito (Hfilo:Lcito) e potássio sangüíneo $(\mathrm{K})$ em frangos de corte suplementados com $\mathrm{KCl} e$ submetidos a estresse calórico

Table 3 - Rectal temperature $(R T)$, hematocrit $(H t)$, heterophil $(H)$, lymphocyte $(L)$, heterophil:Iymphocyte ratio $(H: L)$ and blood potassium (K) in broilers supplemented with $\mathrm{KCl}$ and submitted to heat stress

\begin{tabular}{|c|c|c|c|c|c|c|}
\hline & \multicolumn{6}{|c|}{ Parâmetro (Parameter) } \\
\hline & $\overline{\mathrm{TR}}(R T)\left({ }^{\circ} \mathrm{C}\right)$ & $\mathrm{Ht}(\%)$ & $\mathrm{H}(\%)$ & $\mathrm{L}(\%)$ & $\mathrm{H} / \mathrm{L}$ & $\mathrm{K}(\mathrm{mmol} / \mathrm{L})$ \\
\hline Antes do estresse & $41,00 \mathrm{~B}^{1}$ & $26,35 \mathrm{~B}$ & $27,86 \mathrm{~B}$ & $72,14 \mathrm{~A}$ & $0,41 \mathrm{~B}$ & $4,48 \mathrm{~A}$ \\
\hline Before stress & & & & & & \\
\hline $\begin{array}{l}\text { Depois do estresse } \\
\text { After stress }\end{array}$ & $43,21 \mathrm{~A}$ & $28,32 \mathrm{~A}$ & $40,20 \mathrm{~A}$ & $59,80 \mathrm{~B}$ & $0,74 \mathrm{~A}$ & $3,12 \mathrm{~B}$ \\
\hline $\mathrm{KCl}(\%)$ & & & & & & \\
\hline Controle & & & & & & \\
\hline Control & & & & & & \\
\hline 0,00 & 42,14 & 27,25 & 35,00 & 65,00 & 0,62 & 3,82 \\
\hline Ração & & & & & & \\
\hline Diet & & & & & & \\
\hline 0,50 & 42,00 & 27,25 & 29,44 & 70,56 & 0,46 & 3,63 \\
\hline 1,00 & 42,20 & 28,25 & 31,44 & 68,56 & 0,49 & 3,81 \\
\hline Água & & & & & & \\
\hline Water & & & & & & \\
\hline 0,25 & 42,11 & 27,50 & 38,22 & 61,78 & 0,66 & 3,81 \\
\hline 0,50 & 42,08 & 26,44 & 36,06 & 63,94 & 0,64 & 3,93 \\
\hline $\mathrm{CV}(\%)^{2}$ & 1,39 & 10,80 & 31,93 & 16,47 & 52,08 & 17,96 \\
\hline $\mathrm{CV}(\%)^{2}$ & 0,93 & 8,25 & 14,52 & 7,49 & 24,61 & 17,37 \\
\hline
\end{tabular}

receberam suplementação de $\mathrm{KCl}$. Porém, em aves não suplementadas, o estresse reduziu $(\mathrm{P}<0,01)$ esta contagem. Resultados semelhantes foram obtidos por FURLAN (1992) e CISCATO (1995), os quais atribuíram esta redução à possível alteração na volemia, sugerindo efeito favorável da suplementação de $\mathrm{KCl}$ para frangos submetidos a estresse calórico.
Constatou-se aumento $(\mathrm{P}<0,01)$ na hemoglobina (Tabela 5) após o estresse calórico para aves do grupo controle e aquelas com suplementação de $\mathrm{KCl}$ na ração, diferindo dos resultados de FURLAN (1992) e CISCATO (1995). Após o estresse calórico, as aves que receberam $1,00 \%$ de $\mathrm{KCl}$ na ração apresentaram valores superiores $(\mathrm{P}<0,01)$ aos que

Tabela 4 - Hemácias $\times 10^{6}\left(\mathrm{~mm}^{3}\right)$ em frangos de corte suplementados com $\mathrm{KCl}$ e submetidos a estresse calórico

Table 4 - Erythrocytes $\times 10^{6}\left(\mathrm{~mm}^{3}\right)$ in broilers supplemented with $\mathrm{KCl}$ and submitted to heat stress

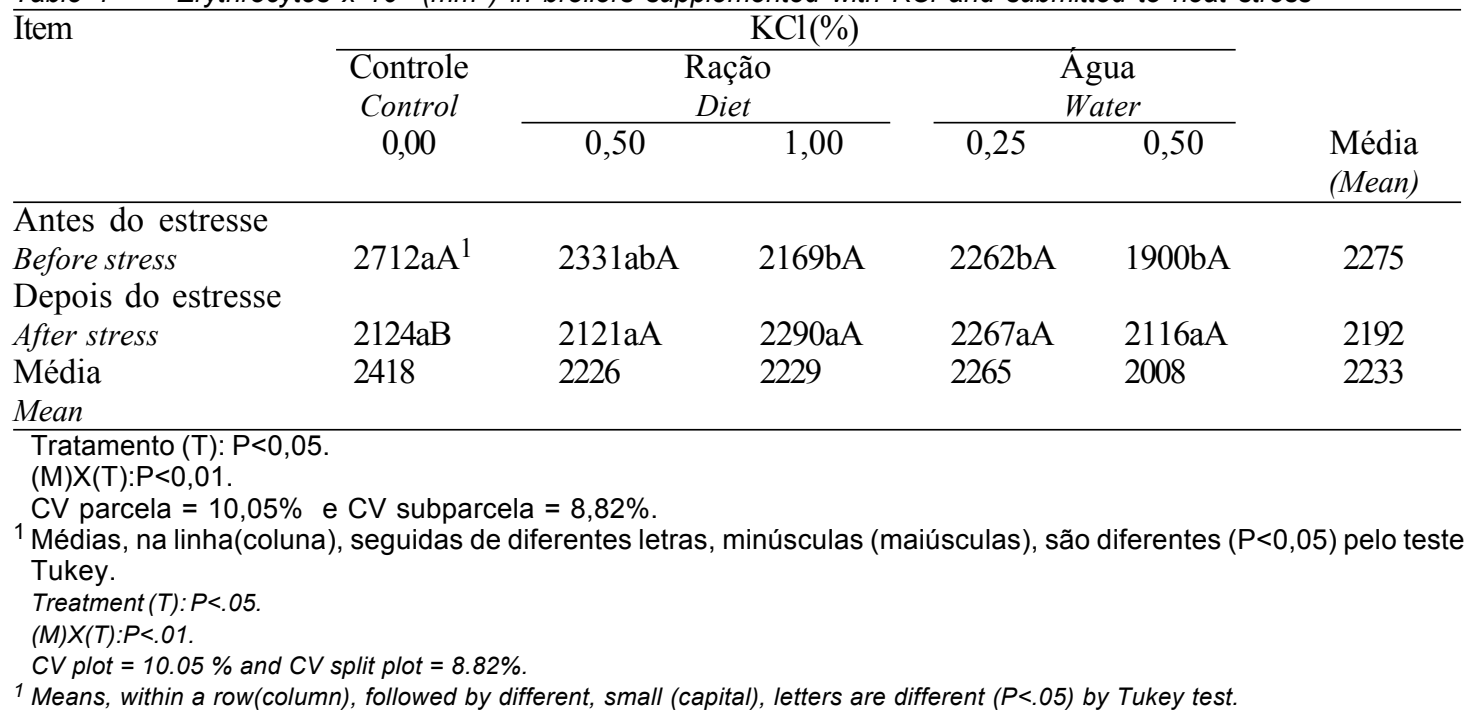


BORGES et al.

Tabela 5 - Hemoglobina $(\mathrm{g} / \mathrm{dl})$ em frangos de corte suplementados com $\mathrm{KCl}$ e submetidos a estresse calórico

Table 5 - Hemoglobin $(\mathrm{g} / \mathrm{dL})$ in broilers supplemented with $\mathrm{KCl}$ and submitted to heat stres

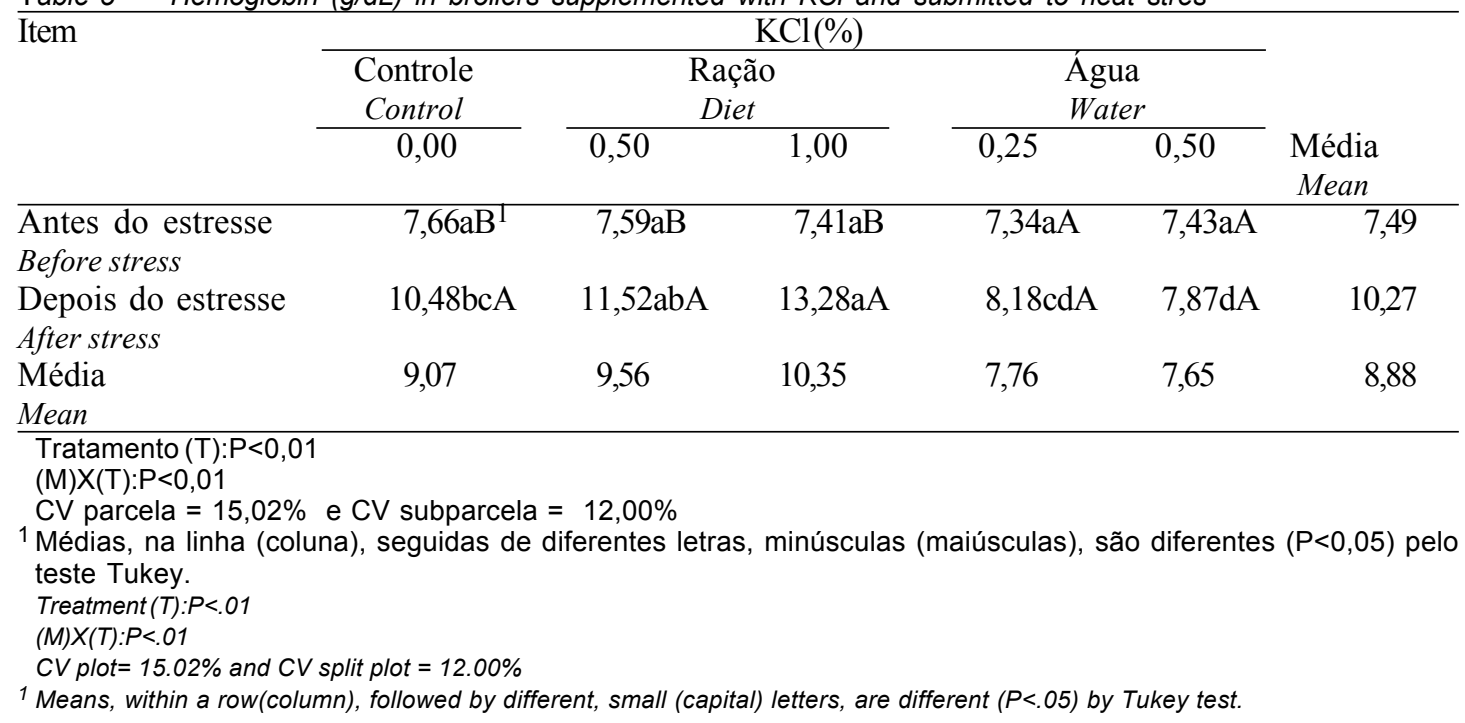

receberam $\mathrm{KCl}$ na água e aos do grupo controle, embora não tenham variado dos resultados das aves suplementadas com $0,50 \% \mathrm{KCl}$ na ração. Provavelmente, o aumento na hemoglobina após o estresse foi compensatório, em razão da redução no número de hemácias. A hemoglobina das aves que receberam $\mathrm{KCl}$ na água de beber não foi influenciada pelo estresse.

Com relação aos níveis séricos de $\mathrm{Na}^{+}$(Tabela 6), observou-se redução $(\mathrm{P}<0,01)$ após o estresse calórico, corroborando os resultados de DEYHIM et al. (1990), BELAY e TEETER (1993) e BOTURA (1993), com frangos de corte submetidos a estresse calórico agudo, e AIT-BOULAHSEN et al. (1995), com frangos sob condições de estresse e recebendo $0,60 \%$ de $\mathrm{KCl}$ na água. A queda nos níveis séricos de $\mathrm{K}^{+}$e $\mathrm{Na}^{+}$ observada neste estudo sugere balanço negativo destes íons em aves estressadas pelo calor, concordando com DEYHIM et al. (1990).

Tabela 6 - Níveis plasmáticos de sódio (mmol/L) em frangos de corte suplementados com $\mathrm{KCl}$ e submetidos a estresse calórico

Table 6 - Plasmatic levels sodium (mmol/L) broilers supplemented with $\mathrm{KCl}$ and submitted to heat stress

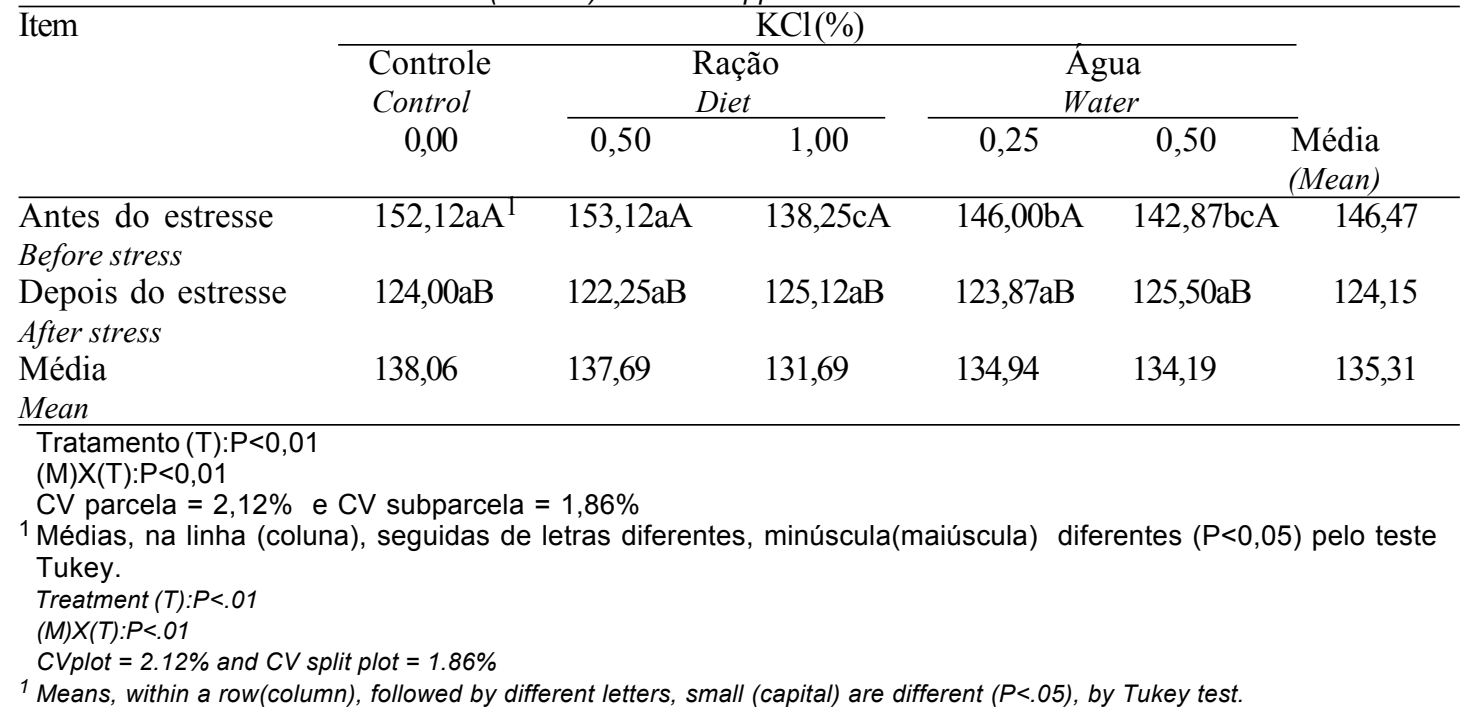




\section{Conclusões}

A suplementação com $\mathrm{KCl}$ para frangos submetidos a estresse calórico na fase final de criação, tanto na ração como na água, independentemente dos níveis adicionados, não influenciou o desempenho, o consumo de água, a relação água/ração e a matéria seca das excretas.

Alterações na temperatura retal e na relação heterófilo/linfócito podem ser usadas como indicativos de estresse calórico. A suplementação de $\mathrm{KCl}$ não influiu na temperatura retal ou na relação heterófilo/ linfócito de frangos de corte estressados pelo calor.

O estresse calórico reduziu os níveis séricos de $\mathrm{K}^{+}$e $\mathrm{Na}^{+}$, o que pode estar ligado a balanço negativo destes minerais com aumento na excreção urinária.

\section{Referências Bibliográficas}

AIT-BOULAHSEN, A., GARLICH, J.D., EDENS, F.W. 1995. Potassium chloride improves the thermotolerance of chickens exposed to acute heat stress. Poult. Sci., 74:75-87.

BANZATTO, D. A., KRONKA, S. N. 1995. Experimentação agricola. Jaboticabal: FUNEP/UNESP. 3 ed., 247p.

BEKER, A., TEETER, R. G. 1994. Drinking water temperature and potassium chloride supplementation effects on broiler body temperature and performance during heat stress. $J$. Appl. Poult. Res., 3:87-92.

BELAY, T., TEETER, R. G. 1993. Broiler water balance and thermobalance during thermoneutral and high ambient temperature exposure. Poult. Sci., 72:116-24.

BORGES, S. A., ARIKI, J., SALVADOR, D. et al. Suplementação de altos níveis de cloreto de potássio em rações de frangos de corte criados durante o verão. In: CONFERÊNCIA APINCO DE CIÊNCIA E TECNOLOGIA AVÍCOLAS, 1996, Curitiba. Anais... Campinas: FACTA, 1996a, p.62.

BORGES, S.A. ARIKI, J., PEDROSO, A.A. et al. Suplementação de altos níveis de cloreto de potássio em rações de frangos de corte criados durante o verão. In: CONFERÊNCIA APINCO DE CIÊNCIA E TECNOLOGIA AVÍCOLAS, 1996, Curitiba. Anais... Campinas: FACTA, 1996b,p.62.

BOTURA, A. P. Variação da concentração de sódio e potássiono soro de frangos de corte submetidos ao estresse calórico. Jaboticabal, FCAV-UNESP, 1993.37p. (Trabalho de graduação), Universidade Estadual de São Paulo, 1993.

CISCATO, L. F. M. Efeito do estresse térmico sobre o equilibrio ácido-básico e outros parâmetros sanguíneos em frangos de corte ascíticos. Jaboticabal: FCAV-UNESP, 1995.41p. (Trabalho de graduação) - Universidade Estadual de São Paulo, 1995.

DEETZ, L. E., RINGROSE, R. C. 1976. Effect of heat stress on the potassium requirement of the hen. Poult. Sci., 55:1765-70.

DEYHIM, F. BELAY, T., TEETER, R.G. et al. 1990. The effect of heat distress on blood gas, plasma and urine concentration of Na, K, Cl of broiler chicks. Poult. Sci., 69:42 (Abstracts).

FURLAN, R. L. Efeitos do estresse hídrico, alimentar e térmico sobre parâmetros físicos e químicos do sangue de cinco linhagens comerciais de frangos de corte. Jaboticabal: FCAVUNESP, 1992. 95p. Dissertação (Mestrado em Zootecnia) Universidade Estadual de São Paulo, 1992.
HULAN, H.W., SIMONS, P.C.M., VAN SCHAGEN, P.J.W. 1986. Effect of altering the cation-aniion $(\mathrm{Na}+\mathrm{K}-\mathrm{Cl})$ and calcium content of the diet on general performance and incidence of tibial dischondroplasia of broiler chickens housed in batteries. Nutr. Rep. Int., 33:397-408.

MACARI, M. FURLAN, R.L., GONZALES, E. 1994. Fisiologia aviária aplicada a frangos de corte. Jaboticabal: FUNEP/ UNESP, 246p.

MAXWELL, M. H., ROBERTSON, G.W., SPENSE, S. et al. 1990. Comparison of haematological values in restricted and ad libitum- fed domestic fowls: red blood cell characteristics. Br. Poult. Sci., 31:407-13.

MAY, J. D., DEATON, J.W., BRANTON, S.L. 1987. Body temperature of acclimated broilers during exposure to high temperature. Poult. Sci., 66: 378-80.

McFARLANE, J. M., CURTIS, S. E., SIMON, J. et al. 1989. Multiple concurrent stressors in chicks. 2. Effects on hematologic, body composition and pathologic traits. Poult. Sci, 68:510-521.

McFARLANE, J. M., CURTIS, S. E. 1989. Multiple concurrent stressors in chicks. 3. Effects on plasma corticosterone and the heterophil/lymphocyte ratio. Poult. Sci., 68:522-527.

NATIONAL RESEARCH COUNCIL - NRC. 1994. Nutrient requirements of poultry. Washington: National Academy Press, 155p.

ROSTAGNO, H.S., SILVA, D.J., COSTA, P.M.A. et al. 1994. Composição de alimentos e exigências nutricionais de aves e suínos (Tabelas Brasileiras). Viçosa: UFV, 60p.

SMITH, M. O., TEETER, R. G. 1989. Effects of sodium and potassium salts on gain, water consumption, and body temperature of 4 to 7 week-old heat stressed broilers. Nut. Rep. Int., 40:161-9.

SMITH, M.O., TEETER, R. G. 1992. Effects of potassium chloride supplementation on growth of heat-distressed broilers. J. Appl. Poult. Res., 1:321-4.

SMITH, M. O., TEETER, R. G. 1993. Carbon dioxide, ammonium chloride, potassium chloride, and performance of heat distressed broilers. J. Appl. Poult. Res., v.2, p.61-6.

TINÔCO, I. F. F. Estresse calórico - meios naturais de condicionamento. In: SIMPÓSIO INTERNACIONAL SOBRE AMBIÊNCIA E INSTALAÇÃO NA AVICULTURA INDUSTRIAL, 1995, Campinas. Anais.... Campinas: FACTA, p.99-108, 1995.

WIERNUSZ, C. J., TEETER, R. G. 1993. Feeding effects on broiler thermobalance during thermoneutral and high ambient temperature exposure. Poult. Sci., 72:1917-24.

WILSON, W. O. 1971. Evaluation of stressor agents in domestic animals. J. Anim. Sci., 32:578-83.

ZULKIFLI, I., SIEGEL, P. B. 1995. Is there a positive side to stress? W. Poult. Sci. J., 51:63-76.

Recebido em: $11 / 03 / 98$

Aceito em:22/10/98 